\title{
BMJ Open Impact of allergic rhinitis on the day-to- day lives of children: insights from an Australian cross-sectional study
}

\author{
Sinthia Bosnic-Anticevich (D) , ${ }^{1}$ Peter Smith, ${ }^{2}$ Michael Abramson, ${ }^{3}$ \\ Charlotte Mary Hespe, ${ }^{4}$ Menai Johnson, ${ }^{5}$ Rodney Stosic, ${ }^{6}$ David B Price (D) ${ }^{7,8}$
}

To cite: Bosnic-Anticevich S, Smith P, Abramson M, et al. Impact of allergic rhinitis on the day-to-day lives of children: insights from an Australian cross-sectional study. BMJ Open 2020;10:e038870. doi:10.1136/ bmjopen-2020-038870

- Prepublication history and additional material for this paper is available online. To view these files, please visit the journal online (http://dx.doi.org/10. 1136/bmjopen-2020-038870)

Received 27 March 2020 Revised 31 August 2020 Accepted 25 September 2020

\section{A Check for updates}

(c) Author(s) (or their employer(s)) 2020. Re-use permitted under CC BY-NC. No commercial re-use. See rights and permissions. Published by BMJ.

For numbered affiliations see end of article.

\section{Correspondence to} Dr Sinthia Bosnic-Anticevich; Sinthia.Bosnic-Anticevich@ sydney.edu.au

\section{ABSTRACT}

Study design and objective Cross-sectional, observational survey to describe the impact of allergic rhinitis (AR) on Australian children (2 to 15 years). Methods Participants $(n=1541)$, parents of children aged 2 to 15 years, provided information on behalf of themselves and one eligible child in their household using a custom-built online questionnaire. Children were allocated to case (AR) or control (No AR) analysis groups based on a validated screening questionnaire.

Statistical methods The study sample was stratified on age: primary analysis population (6 to 15 years, $n=1111$; $A R=797$, No AR=314); exploratory population (2 to 5 years). The primary endpoint, parent-perceived burden, was quantified using a validated measure of health status and analysed via comparison of means.

Results The majority of AR cases were treated (730/797; $90.3 \%$ ) and classified as having moderate-severe, intermittent AR $(549 / 797 ; 68.9 \%)$. Half reported adequate symptom control in the prior 2 weeks (389/797; 48.8\%; $\mathrm{OR}=4.04 ; 95 \% \mathrm{Cl}(\mathrm{Cl}) 2.24$ to 7.31 ). Having AR was associated with worse overall health status $(7.4 \mathrm{vs}$ 8.4, mean difference (least squares mean difference $($ LSMD) $)=-0.99 ; 95 \% \mathrm{Cl}-1.18$ to -0.79 ), fewer days being happy (22.2 vs 25.9 , LSMD $=-3.68 ; 95 \% \mathrm{Cl}-4.82$ to -2.54 ) and more days of poor physical (2.82 vs 0.78 , LSMD $=2.04 ; 95 \% \mathrm{Cl} 1.61$ to 2.47 ) and emotional (2.14 vs $0.67, \mathrm{LSMD}=1.47 ; 95 \% \mathrm{Cl} 1.02$ to -1.92 ) health compared with not having AR. All of these outcomes were significantly $(p<0.05)$ worse in children who reported inadequate symptom control. Having AR negatively impacted on schoolwork, sleep and other activities, and increased the likelihood of having comorbidities. Conclusion The parent-perceived burden of AR in Australian children is high and it impacts many areas of day-to-day living. Inadequate symptom control is a key driver of the extent of this impact. Opportunities to optimise the management of AR in children include the adoption of self-assessment tools to gauge and monitor adequacy of symptom control.

\section{INTRODUCTION}

Allergic rhinitis (AR), an IgE-mediated, chronic inflammatory disorder affecting the nasal mucosa, is characterised by episodes of repeated sneezing, rhinorrhoea and nasal congestion, often accompanied by itching of

\section{Strengths and limitations of this study}

- This study used objective measures to quantify the negative impact of paediatric allergic rhinitis on health status, emotional well-being, physical health, school and sleep.

- All data were parent-reported and were collected using a customised online survey questionnaire, which included relevant validated tools.

- The International Study of Asthma and Allergies in Childhood questionnaire provided the basis for screening participants and was used to allocate children to case or control groups for analysis.

- The data revealed some interesting findings, notably the significant role of adequacy of symptom control, and raised questions about the level of parental knowledge regarding the medication their child is taking.

- The validity of the data was limited due to methodological constrains, including online sampling, inability to verify sample representativeness and collection of parent-reported data rather than those of the child directly.

the eyes, nose and palate. ${ }^{1}$ Pharmacological treatment aims to achieve symptom control, but current Allergic Rhinitis and its Impact on Asthma (ARIA) guidelines suggest the need to take account of multiple factors beyond efficacy, speed of onset and safety when selecting pharmacotherapy for patients to encompass patient preferences, symptom severity, prior treatments, self-management strategies and the effects of AR on sleep and work productivity. ${ }^{2}$ This reflects an increasing recognition that the interlinked concepts of disease severity and control are complex in AR. Rather than equating severity directly with physiological function, patients with $\mathrm{AR}$ tend to equate severity with the negative impact that the allergies have on their lives. ${ }^{3}$ Understanding what drives this negative impact of AR is important; and is further heightened where treatments for this condition are available in the pharmacy setting where patients often self-select. 
Health-related quality of life (HR-QoL) is a complex and multidimensional concept used as a marker of disease impact beyond clinical impact, morbidity or mortality. It is often used to capture subjective perceptions and objective assessment of a patient's health and well-being. ${ }^{4} \mathrm{HR}-\mathrm{QoL}$ in children with AR is an important and emerging area of interest, primarily due to the fact that the impact of AR on the day-to-day lives of individuals can be felt beyond the severity of symptoms experienced. In their review of 27 studies of children with AR, aged 10 to 19 years, Blaiss et a $\tilde{l}$ highlighted the negative impact of AR on several aspects of day-to-day living including: daily functioning, sleep, absenteeism, school productivity and academic performance. Adolescents with AR have high rates of somatisation, anxiety and depression, less resistance to stressful situations, and exhibit more hostility, impulsivity and rapid changes in interest. Parental assessment of the impact of AR on the day-to-day lives of children with AR indicates that AR makes their child unhappy, upset, angry and embarrassed. ${ }^{6}$ In practical terms, HR-QoL can be used to describe the way in which health status affects quality of life. ${ }^{7}$ Some of the most important research exploring the impact of AR on the day-to-day lives of children in the USA have used the concept of 'health status' as a means of determining the burden of $\mathrm{AR}^{8}$ It is in recognition of this research, and the high prevalence of $\mathrm{AR}$, that we focus on AR in children.

Previous Australian data reported a prevalence of AR of approximately $12.9 \%$ in children aged 6 to 7 years and $19.3 \%$ in children aged 13 to 14 years. ${ }^{9}$ More recent data suggest a higher, and rising, ${ }^{10}$ prevalence: $15.1 \%$ to $37.8 \%$ in adolescents aged 12 to 15 years in Europe ${ }^{11}$ and $24.8 \%$ among children aged 14 to 17 years in the USA. ${ }^{12}$ Data from an Australian longitudinal birth cohort study (Perth Infant Asthma Follow-up (PIAF) study) demonstrated a rapid increase in the development of AR over childhood (7\% at age 6 years, 18\% at age 11 years and increasing to $24 \%$ by age 18 years) ${ }^{13}$ However, despite this high prevalence, published Australian data on the impact and management of AR in children are minimal and outdated. ${ }^{14}$

To address this gap, we conducted a national, online survey to generate contemporary data describing the burden of AR on the day-to-day lives of Australian children (2 to 15 years), with the aim of identifying gaps and opportunities for optimising care in the future. Inherent difficulties in properly identifying AR in young children (2 to 5 years) were addressed by the study sample being stratified on age with the primary analysis population encompassing children 6 to 15 years and an exploratory population encompassing the younger children (2 to 5 years). We report here the primary study results.

\section{METHODS}

The survey was conducted between 15 October 2018 and 12 November 2018. The study sample was derived from three ISO-accredited research-only panels of respondents for online consumer research in Australia (Ipsos i-Say 180000 members, Research Now/Survey Sampling International 400000 members and Pure Profile 250 000 members). Panel members completed a series of screening questions, including inclusion and exclusion criteria, and eligible respondents provided informed consent prior to accessing the survey. Eligible participants were aged 21 years or over, currently residing in Australia and the parent/guardian of at least one child aged 2 to 15 years. Participants provided information on behalf of themselves and one eligible child in their household. Participants with multiple eligible children were randomly allocated a specific child on which to answer questions.

\section{Data collection and cohort description}

All data were parent-reported, and collected using a customised online survey questionnaire, which was selfadministered once. The questionnaire (online supplemental file 1) comprised a series of closed-answer questions, incorporating relevant validated tools and other questions developed empirically through review of the AR literature and other health surveys.

The questionnaire explored 11 domains: (1) screening (International Study of Asthma and Allergies in Childhood (ISAAC) questionnaire), ${ }^{15}$ (2) family medical history, (3) parent-perceived burden (as assessed by the validated single health status question; ${ }^{16}$ and the validated Healthy Days questionnaire ${ }^{17}$ and impact of AR on day-to-day living (adapted from Pediatric Allergies in America Survey)), ${ }^{18}$ (4) beliefs about medicines (Beliefs about Medicines questionnaire), ${ }^{19}$ (5) knowledge and beliefs about allergies (knowledge, attitude and practice questions in AR and asthma), ${ }^{20-22}$ (6) AR classification (ARIA criteria), ${ }^{123}$ (7) AR diagnosis, (8) AR triggers and testing, (9) AR symptoms (Contre les MAladies Chroniques pour un VIeillissement Actif (MACVIA)-ARIA validated visual analogue scales (VAS) ${ }^{324} 25$ ), (10) symptom control (Control of Allergic Rhinitis and Asthma Test for Children ${ }^{26}$ and (11) AR management strategies. The length of the questionnaire was a key consideration; to minimise bias resulting from questionnaire fatigue, data collected about the survey respondents (parents/guardians) were minimal, with the majority of data relating to the specified child on whose behalf the questionnaire was being completed.

The ISAAC questionnaire ${ }^{15}$ provided the basis for screening participants and was used to allocate respondents' children to case or control groups for analysis. Cases (AR) were defined as children with symptoms of AR that were not associated with a cold/influenza, and controls (No AR) were defined as children without symptoms of AR. Within the AR group, a subgroup was defined based on information provided that the child was currently using an allergy medication, where "treated AR' had selected one or more types of medicines from a list, while those allocated to 'untreated AR' had selected either 'none' or 'don't know'. 
Burden of AR was determined based on four questions: a single validated question, 'In general, how would you describe your child's health?' to provide a measure of health status, and three questions to assess the number of healthy days per month, as reflected in the number of the number of days in the last month the child could be described as being (a) healthy (happy and full of energy), (b) had poor physical health or (c) had poor emotional health. These four questions were derived from the validated Centers for Disease Control and Prevention (CDC) Healthy Days Core Module ${ }^{17}$ and the Pediatric Allergies in America Survey. ${ }^{18}$ The original, validated, health status question was answered using a 5-point Likert scale (excellent, very good, good, fair or poor). ${ }^{17}$ To provide a quantitative value for statistical analyses, it was administered using a $10 \mathrm{~cm}$ VAS ( $0=$ poor; $10=$ excellent). To determine the impact of AR on day-to-day living, questions used in the Pediatric Allergies in America Survey ${ }^{18}$ were modified in order to capture data relating to performance at school and in other activities, sleep duration, sleep quality, absenteeism and presenteeism. Taking into consideration the lower target age of the children in the survey was 2 years, for pragmatic reasons the questionnaire was answered by an adult on behalf of the child, hence all findings are reported as being parent-perceived.

\section{Patient and public involvement}

The research question and outcomes measures were informed by the results of prior published research in paediatric AR patients. However, at the time of protocol development, a review had identified a number of important data gaps, noting few recent data on the impact of AR in adolescents and questioned the relevance of available evaluations of HR-QoL in the current social landscape. ${ }^{5}$ Patients were not involved in the design of the survey questionnaire, the conduct of the study or reporting of the results.

\section{Sample size}

The primary endpoint was parent-perceived burden (health status) in children aged 6 to 15 years in case (AR) versus control groups (no AR). It was determined that the study would require a sample of at least 1000 children for univariate logistic regression and 1100 children for multivariable logistic regression, assuming the sample was children aged 6 to 15 years, with an expected symptom prevalence of $4 \%\left(4.45 \%,{ }^{27}\right.$ an OR of 1.5 (1.5 among children aged 6 to 17 years $\left.^{5}\right)$, an alpha of $5 \%$ (95\% CI), a power of $80 \%$ and a $30 \%$ multiple correlation with other covariates. To allow for the exploratory analysis in young children, the sample was extended proportionately to the age range 2 to 5 to maintain the same power. Sample selection quotas were stratified based on the child's age, gender, geographical location and meeting case/control criteria. Children meeting case criteria were also stratified based on AR classification, management and management type.

\section{Statistical analysis}

Variables included prevalence, family history, parentperceived burden ${ }^{16}{ }^{17}$ and impact, ${ }^{18}$ symptoms, diagnosis, triggers and management. Baseline demographic variables (child's age and gender) were used as criteria to test for differences. All information was summarised using descriptive statistics for continuous data and frequency tables for categorical data. Summaries were provided based on relevant analysis samples: controls (No AR), all cases (AR), AR cases treated and AR cases not treated. Observations with missing values were excluded and answers of 'Don't Know' were replaced with missing values.

Data were analysed using the $\chi^{2}$ test for two-way tables and by binary logistic or multinomial models for variables with more than two levels. All statistical analyses were performed at the 5\% significance level using two-sided tests or two-sided CIs. For two-way tables, OR with 95\% $\mathrm{CI}$ and $\mathrm{p}$ values were created to quantify any associations. Additional analyses were conducted to understand the relationships, multi-level associations and interactions and control for potentially confounding factors. The analysis was built progressively through phases, by first understanding the univariate relationships (for continuous variables) or associations (for categorical variables), and then incorporating analysis and modelling which brought in more than one variable to account for interactions or potentially confounding factors. The variables incorporated in the secondary modelling included variables identified in the initial analysis with a cut-off of $\mathrm{p}<0.05$.

The level of parent-perceived burden was determined via comparison of means, $95 \%$ CI for the means and their differences and $\mathrm{t}$ or $\mathrm{z}$ tests for the following groups: cases (AR) versus controls (No AR), cases (AR) treated versus not treated, and cases (AR) with good versus poor symptom control. Where there were more than two groups, analysis of variance was applied to test for a significant difference between groups. Depending on the group, analyses conducted were: distribution and comparison of means (least squares means (LSM)), generalised linear models (GLM), contingency tables and OR, and GLM model with interactions. This analysis was applied to each of the four questions used to determine burden: health status, the number of healthy days in the last 30 days and the number of unhealthy days in the last 30 days (a combined mean of physically unhealthy days and emotionally unhealthy days). ${ }^{17}$ Covariates identified based on the outcome of the baseline variables analyses were then included as independent variables along with group allocation (AR or No AR) and treatment type in multiple linear regression of the above mean parentperceived burden measures. Summaries and statistical analyses were generated using Q-research software (V.5.3.2, Displayr, Chicago, Illinois) and SAS (V.9.4, SAS Institute, Cary, North Carolina). 


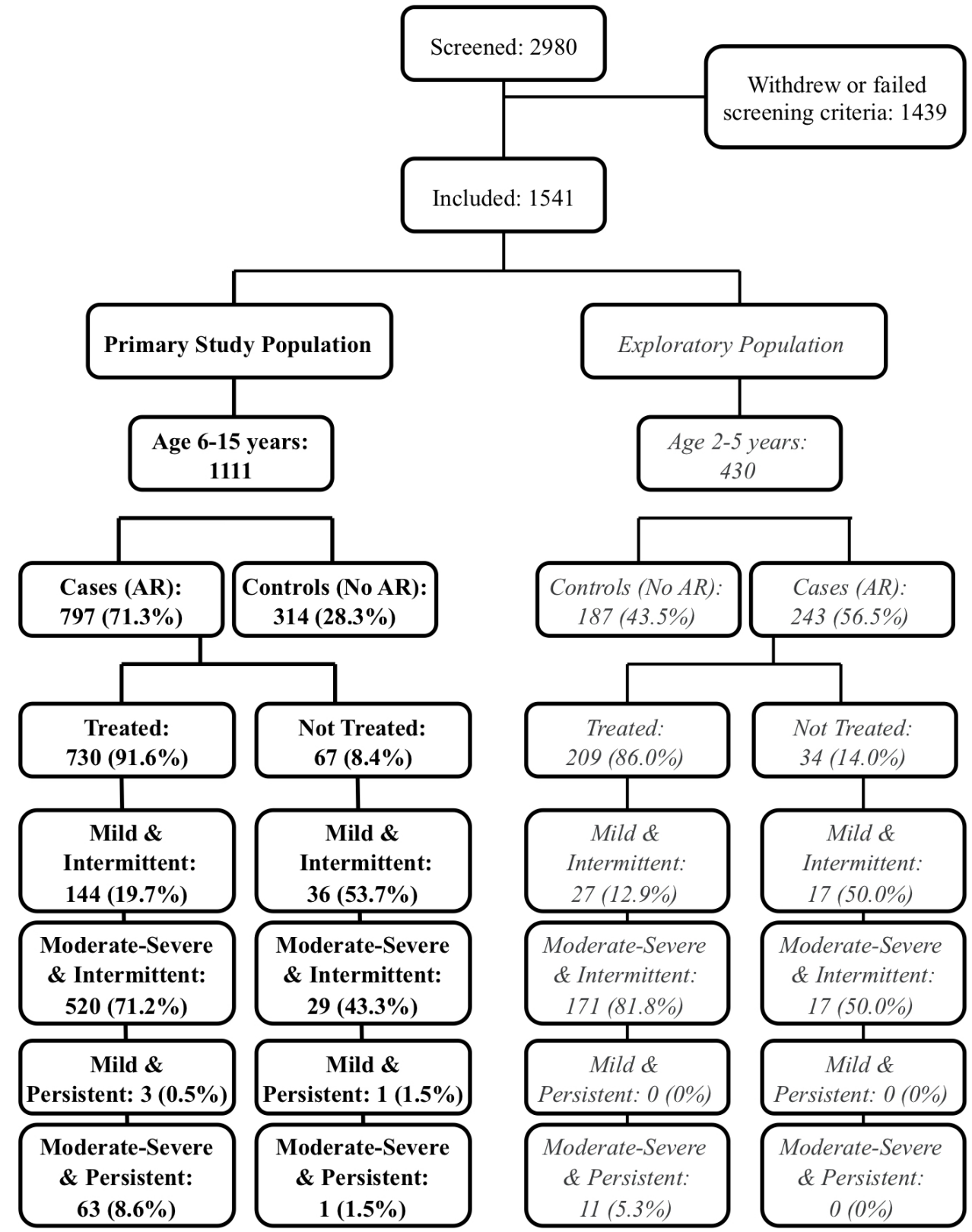

Figure 1 STROBE flowchart of participants, group allocation: AR/No AR based on the International Study of Asthma and Allergies in Childhood questionnaire $;^{15} \mathrm{mild} /$ moderate-severe and intermittent/persistent based on the Allergic Rhinitis and its Impact on Asthma Criteria: ${ }^{123}$ and treated/not-treated based on parental report of current allergy medicine use. AR, allergic rhinitis.

\section{RESULTS}

Of the 2980 potential participants screened, 1541 met the inclusion criteria and completed the survey. Approximately two-thirds of respondent were female and their mean age was 42 years (online supplemental table 1 ). The primary analysis sample comprised 1111 children, aged 6 to 15 years (figure 1); the majority of AR cases were being treated $(730 / 797 ; 90.3 \%)$ and were classified as having moderate-severe, intermittent AR based on the ARIA criteria (549/797; 68.9\%).

\section{Demographics}

There was no statistically significant difference between the mean ages of AR case and control children. Children treated for AR, were older than those not treated (11.5 vs 10.1 years, $95 \%$ CI -2.12 to -0.53$)$. Parental AR was associated with significantly increased odds of AR in their offspring (OR 5.21, 95\% CI 3.78 to 7.18 ) and there were statistically significant relationships between having AR and sinusitis, asthma, cough, recurrent wheezing, hives, nasal polyps or food allergy. Children with AR were significantly more likely to have undergone ear, nose and throat procedures than those without AR (table 1). In the past 12 months, doctor visits were reported significantly more frequently in children with AR than those without (3.2 vs 1.4 visits, $\mathrm{p}<0.001$ ). After hay fever, the three most common reasons for seeking a doctor's advice in children 
Table 1 Medical history and doctor visits. Data presented as N (\%)

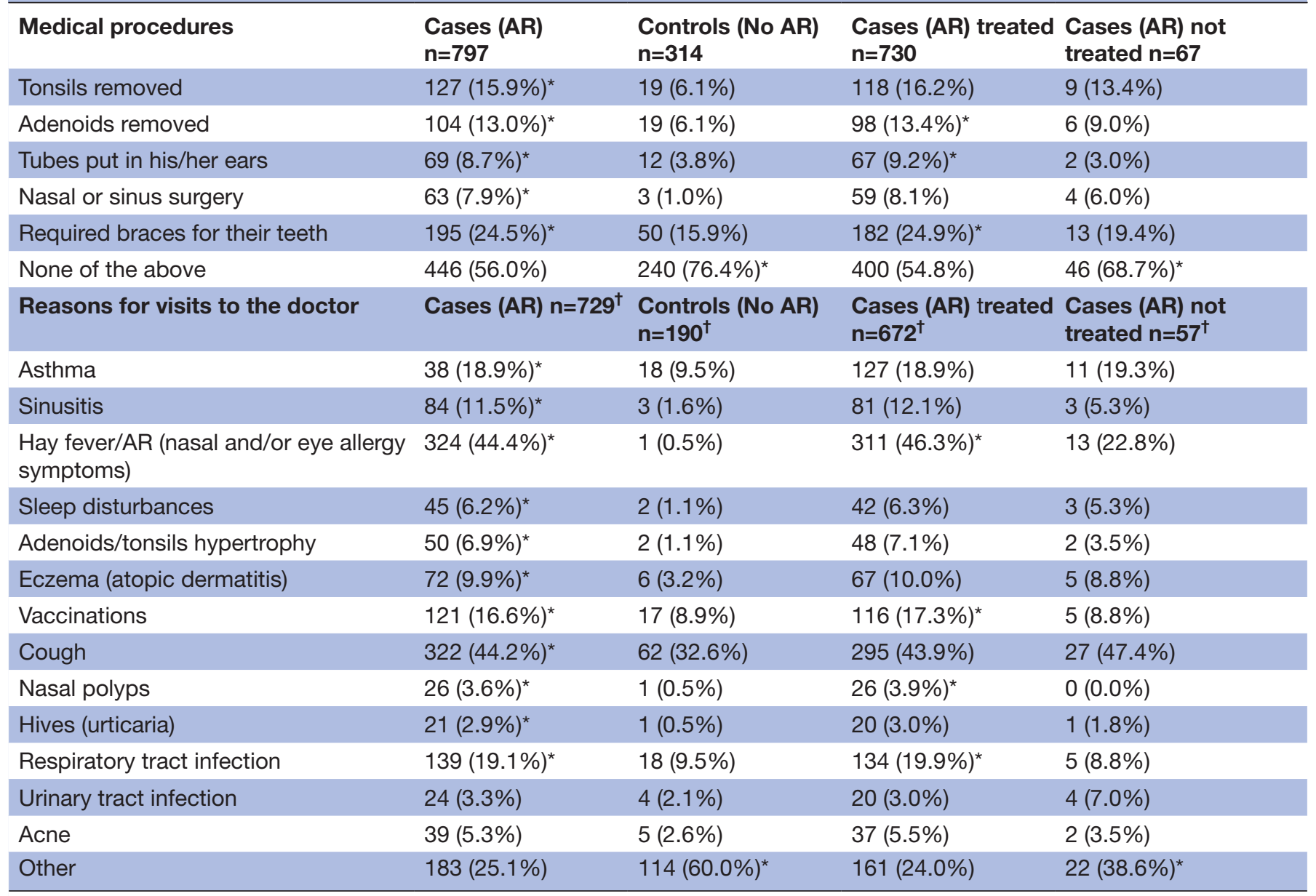

*Statistically significant difference between groups (cases versus controls; cases treated versus not treated) at $95 \% \mathrm{Cl}$. The list of reasons was prespecified in the survey questionnaire.

†Sample size smaller than the total population due to missing data. $\mathrm{AR}$, allergic rhinitis.

with AR were cough, respiratory tract infections and asthma, all of which were significantly higher than in children without AR (table 1).

\section{AR symptoms and adequacy of control}

The average age at symptom onset was 6.7 years (treated AR) and 6.2 years (untreated AR). Parents of children with AR reported that runny nose, nasal congestion, itchy eyes and repeated sneezing were the four most bothersome symptoms (online supplemental table 2). When the level of bother from each symptom was reported using a $10 \mathrm{~cm}$ VAS, facial pain, difficulty getting to sleep, disturbed sleep, distractibility and irritability were the most frequently reported moderate-severely bothersome symptoms (figure 2).

Overall, half of the children with AR were reported to have adequate symptom control (VAS score of $\leq 5$ on a $10 \mathrm{~cm}$ scale) over the past 2 weeks $(389 / 797 ; 48.8 \%)$. The majority of children currently treating their AR were using tablets/liquids $(453 / 730,62 \%)$, half were using nasal sprays $(365 / 730,50 \%)$ and one in three were using eye drops $(211 / 730,29 \%)$. The majority of children who were treating their AR had been advised to do so by a healthcare professional (general practitioner: 372/730 (51\%), pharmacist: $175 / 730(24 \%)$ and specialist: $80 / 730$ $(11 \%))$. However $10 \%(73 / 730)$ of children were being managed based on the decisions of their parents.

Irrespective of the medication class, the majority of children began using their medication either at the onset of symptoms or the onset of the allergy season (online supplemental table 3). Over one-third of children $(263 / 730,36 \%)$ who had been identified as treating their AR had taken medication on the day of the survey. The mean bother score was higher in these children (6.14 \pm 2.04$)$ than in those who had not taken their medication that day $(3.20 \pm 2.68)$.

\section{Burden and impact of AR}

Based on the single validated question, 'In general how would you describe your child's health?' to determine health status, children with AR had significantly higher parent-perceived burden than did those without AR (figure 3). Subgroup analyses showed that these differences remained statistically significant for comparisons of 


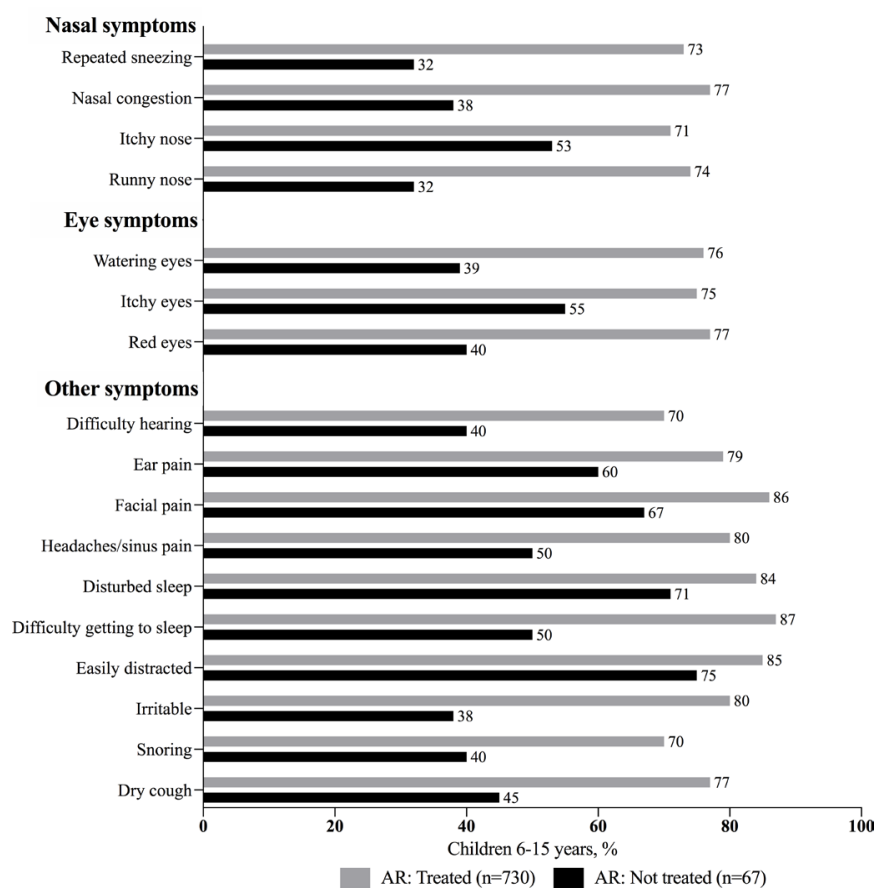

Figure 2 Proportion of children with AR in whom symptoms were moderate-severely bothersome*. ${ }^{*}$ Defined as a score between 6 and 10 on a $10 \mathrm{~cm}$ visual analogue scale $(0 \mathrm{~cm}=$ not at all bothersome and $10 \mathrm{~cm}=$ extremely bothersome (as bad as they can get)). ${ }^{34} \mathrm{AR}$, allergic rhinitis.

children with inadequate symptom control versus good symptom control and of children with moderate-severe versus mild AR, but not for treated versus untreated cases (figure 3). Having AR, poor symptom control and moderate-to-severe disease were also associated with fewer

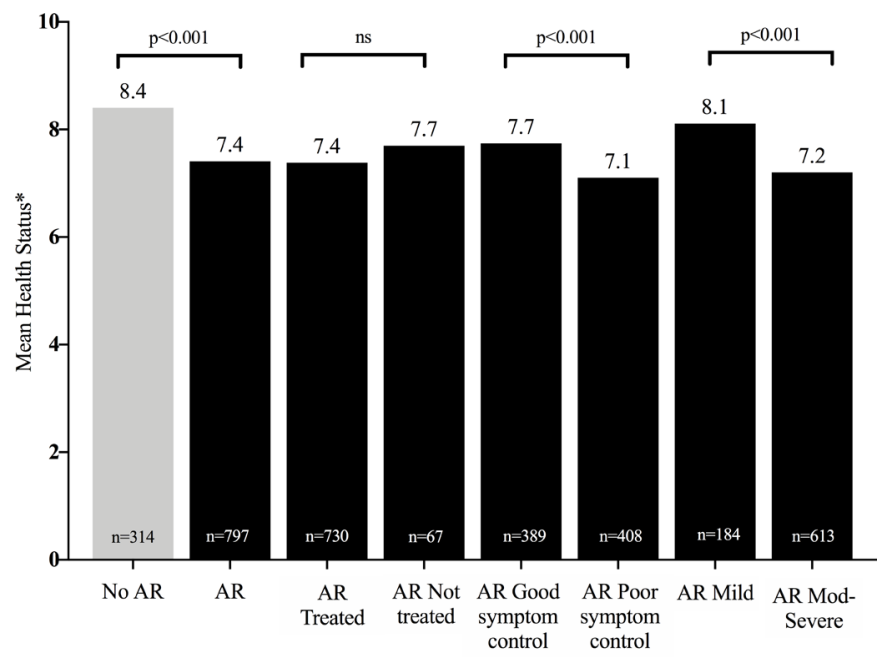

Figure 3 Parent-perceived burden: health status in children aged 6 to 15 years. *Health status was based on the single question, 'In general, how would you describe your child's health?', ${ }^{16} 18$ adapted to be answered on a $10 \mathrm{~cm}$ VAS $(0=$ poor health and $10=$ good health). Mean score was derived from the cut-off criteria: VAS $<2=$ very poor; $2 \leq \mathrm{VAS}<4=$ poor, $4 \leq \mathrm{VAS}<6=$ good, $6 \leq \mathrm{VAS}<8=$ very good and $8 \leq \mathrm{VAS} \leq 10=$ excellent). AR, allergic rhinitis; ns, not significant; VAS, visual analogue scale.

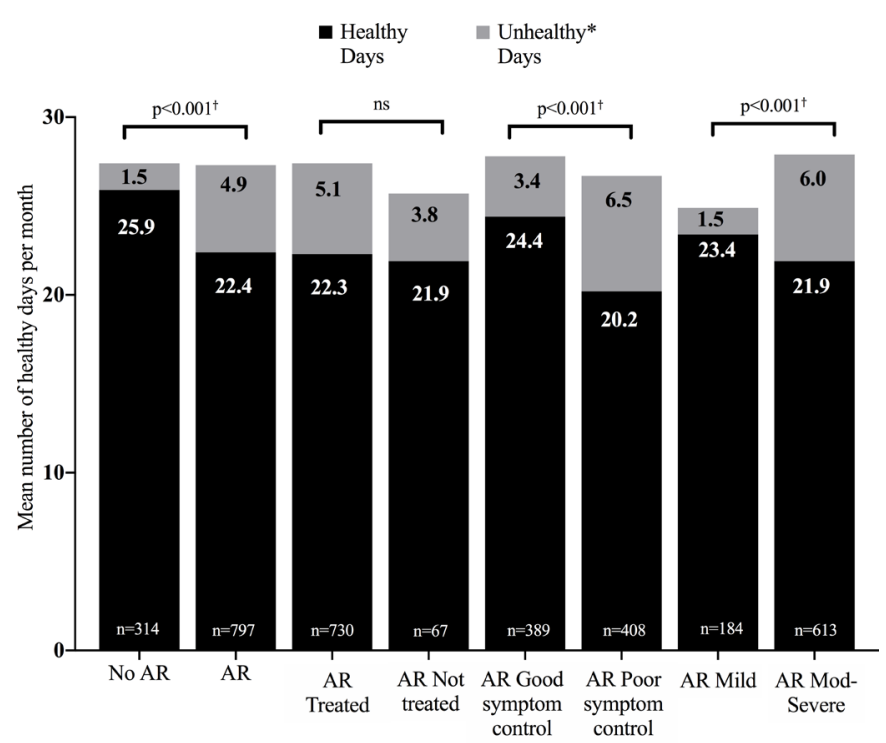

Figure 4 Parent-perceived burden: healthy and unhealthy days per month in children aged 6 to 15 years. The number of days in the last month the child was either healthy (happy and full of energy), had poor physical health or had poor emotional health were measured based on questions derived from the Centers for Disease Control and Prevention's Healthy Days Core Module ${ }^{17}$ and the Pediatric Allergies in America Survey. ${ }^{18}$ *Unhealthy days $=$ number of days of poor emotional health and number of days of poor physical health combined. †Statistically significant difference between groups for each metric (healthy days and unhealthy days). $A R$, allergic rhinitis.

healthy days and more unhealthy days (poor emotional and physical health) per month (figure 4). There was a significant association between AR classification, treatment and adequacy of symptom control (figure 5). Based on health status, parent-perceived burden was least in untreated children who had mild AR and good symptom control (LSM health score: $8.24 ; 95 \%$ CI 7.68 to 8.80 ) and greatest in untreated children who had moderate-severe $\mathrm{AR}$ and inadequate symptom control (LSM health score: $6.58 ; 95 \%$ CI 5.72 to 7.44$)$.

The burden of AR was greatest in children with co-morbidities (figure 6A). Parent-perceived burden was lowest in children with AR who also had other conditions (LSM $7.27 ; 95 \%$ CI 7.07 to 7.47 ), but was not significantly lower than in children with AR and no other conditions (LSM 7.47; 95\% CI 7.32 to 7.62). Parent-perceived burden was significantly lower in children with $\mathrm{AR}$, either with or without comorbidities, than in those without AR with (LSM 8.03; 95\% CI 7.78 to 8.53) or without (LSM 8.58; 95\% CI 8.38 to 8.78 ) comorbidities. This trend was also seen in the number of healthy days (figure 6B), days of poor physical health and days of poor emotional health per month (figure 6C).

Having AR versus not having it was associated with significantly reduced ability to perform schoolwork and other activities. Children accomplished less than they would usually have done at school or in other activities, and a reduced level of care was taken when performing 


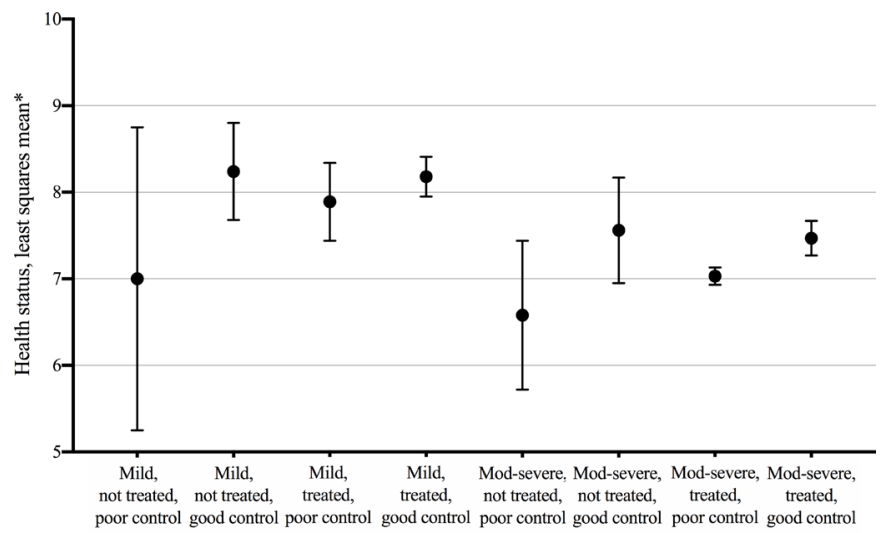

Figure 5 Parent-perceived burden: interaction between AR classification, receipt of treatment and adequacy of symptom control in children with AR aged 6 to 15 years. *Health status was based on the single question, 'In general, how would you describe your child's health?', ${ }^{16} 18$ adapted to be answered on a $10 \mathrm{~cm}$ VAS $(0=$ poor health and $10=$ good health). Mean score was derived from the cut-off criteria: VAS $<2=$ very poor; $2 \leq \mathrm{VAS}<4=$ poor, $4 \leq \mathrm{VAS}<6=$ good, $6 \leq \mathrm{VAS}<8=$ very good, $8 \leq \mathrm{VAS} \leq 10=$ excellent. Statistically significant differences in health status between seven comparisons: treated and mild AR and good control versus treated and moderate-severe AR and good control $(p=0.0008)$, treated and mild AR and good control versus treated and moderatesevere AR and poor control $(p<0.0001)$, treated and mild AR and good control versus not-treated and moderate-severe $A R$ and poor control $(p=0.0081)$, treated and mild AR and poor control versus treated and moderate-severe $A R$ and poor control $(p=0.0126)$, not-treated and mild AR and good control versus treated and moderate-severe AR and poor control $(p=0.001)$, not-treated and mild AR and good control versus not-treated and moderate-severe $A R$ and poor control $(p=0.0181)$, treated and moderate-severe AR and good control versus treated and moderate-severe $A R$ and poor control $(p=0.0095)$. AR, allergic rhinitis; Mod, moderate; VAS, visual analogue scale.

schoolwork and other activities (table 2). Between-group comparisons showed that, among all children with AR, these activities were affected in significantly more children who had poor symptom control (versus good symptom control), in those with moderate-to-severe symptoms (versus mild symptoms) and those who were currently treating their AR (versus not currently treating) (table 2). Having AR was also associated with a reduced duration of sleep ( 8 hours or less per night: AR 494/797 $(62 \%)$ vs No AR 126/314 (40\%), p<0.05), poorer sleep quality and higher rates of absenteeism (table 2).

\section{Parents' knowledge and beliefs about AR}

As part of the survey, parents were asked if their child ever had hay fever. These data were then compared with children classified as having AR (AR cases) based on the answers that the parents gave to the ISAAC questions ${ }^{15}$ later in the survey. AR was not always recognised by the parents: overall, a history of $\mathrm{AR}$ was not reported in $118 / 797(15 \%)$ of the children who were classified as having AR based on the ISAAC questions. Most parents
$(669 / 797 ; 84 \%)$ believed that AR could significantly impair well-being, but their understanding of causes was poor; $375 / 797(47 \%)$ believed it could only be caused by a reaction to something in the air outdoors, $128 / 797$ $(16 \%)$ believed that it was caused by a virus and $112 / 7979$ $(14 \%)$ believed that it was contagious. Parents who had sought advice from a healthcare professional had primarily received written or verbal information about available treatment options $(274 / 797 ; 34 \%)$, administration approaches (dosing regimen (169/797, 21\%), how to use $(191 / 797,24 \%)$ and side effects $(191 / 797$, $24 \%))$. Few received information about the condition itself $(117 / 797,15 \%)$, and two-third $(509 / 797,64 \%)$ of parents indicated that they would benefit from having more information about AR.

\section{DISCUSSION}

This study has confirmed that having AR significantly impacts a child's life as reported by parents. Among Australian children, aged 6 to 15 years, having AR was associated with greater parent-perceived burden, lower health status, fewer days of being healthy and more days of being unhealthy (poor physical or emotional health). It significantly reduced the child's ability to perform schoolwork and other activities, was associated with children accomplishing less than they would usually have done at school or in other activities, and reduced the level of care taken when performing schoolwork and other activities. Absenteeism and the likelihood of having comorbidities were increased, while sleep duration and quality were reduced.

Parent-perceived burden was highest in children who were not treated, who also had moderate-severe AR and reported inadequate symptom control. Statistical modelling, undertaken to help better define what was contributing to this parent-reported burden, found the most important overall factor leading to a lower health status was inadequate symptom control. Despite the majority of children being treated, half had inadequate symptom control (VAS score of $>5$ on a $10 \mathrm{~cm}$ scale). Parents reported that a large proportion of children used their medication only after their symptoms had started or when symptoms were very bothersome. While this may reflect that the majority of treated children were classified as having intermittent AR (mild: $19.7 \%$, moderate-severe: $71.2 \%$ ), and reflects on-demand treatment approaches observed in adults with $\mathrm{AR},{ }^{28}$ it does not account for optimal pharmacology. For example, oral antihistamines have a rapid onset of action (1 to 2 hours), while for intranasal corticosteroids (INCS) the onset of action is 7 to 12 hours and it can take up to 2 weeks for maximum benefit to be achieved. ${ }^{29}$ Established guidelines support that use of INCS on an as-needed basis is less effective than continuous use. ${ }^{30}$

In an attempt to determine the relationship between treatment and impact of AR, participants were asked to report on whether their child had used their allergy medication that day, while also reporting on how bothersome 
(A) Overall health status*

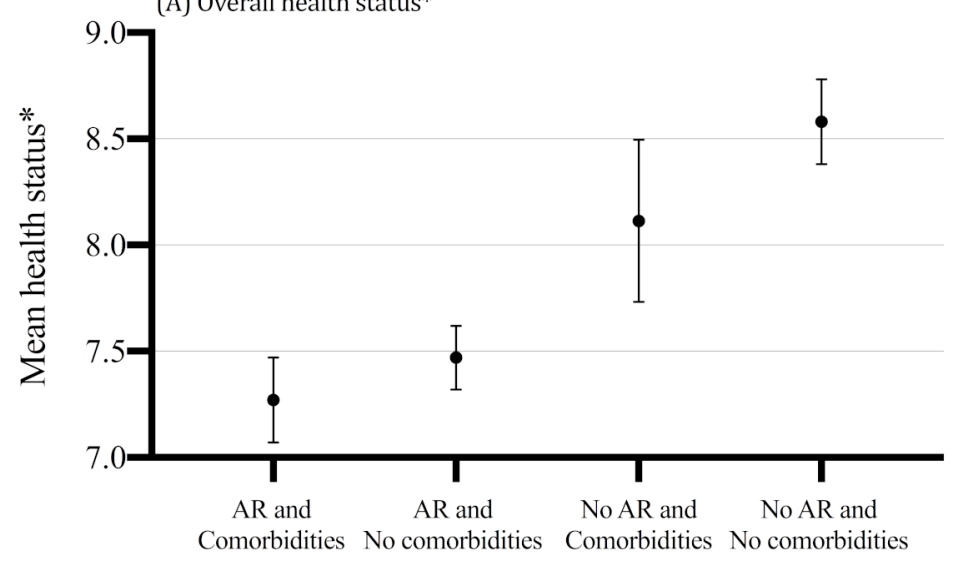

(B) Number of healthy days in the last month ${ }^{\dagger}$

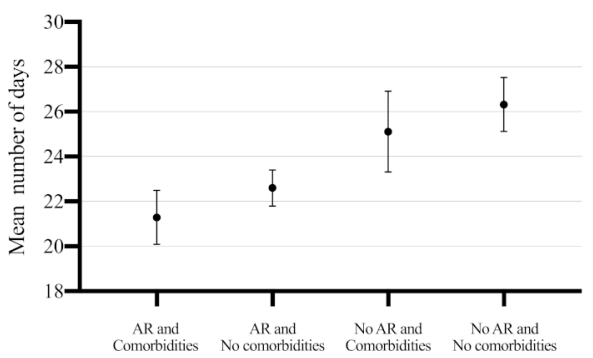

(C) Number of unhealthy days ${ }^{\ddagger}$ in the last month ${ }^{\dagger}$

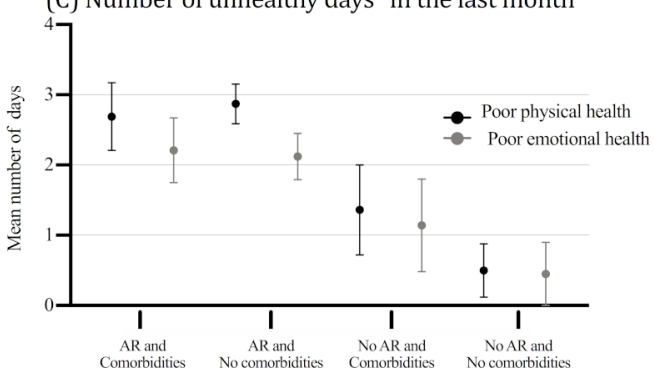

Figure 6 Parent-perceived burden: interaction between AR and comorbidities in children aged 6 to 15 years. ${ }^{*}$ Health status was based on the single question, 'In general, how would you describe your child's health?', ${ }^{18} 18$ adapted to be answered on a $10 \mathrm{~cm}$ VAS ( $0=$ poor health and $10=$ good health). Mean score was derived from the cut-off criteria: $V A S<2=$ very poor, $2 \leq \mathrm{VAS}<4=$ poor, $4 \leq \mathrm{VAS}<6=$ good, $6 \leq \mathrm{VAS}<8=$ very good, and $8 \leq \mathrm{VAS} \leq 10=$ excellent. $\dagger$ The number of days in the last month the child was healthy (happy and full of energy), had poor physical health and had poor emotional health were measured based on questions derived from the Centers for Disease Control and Prevention's Healthy Days Core Module ${ }^{17}$ and the Pediatric Allergies in America Survey ${ }^{18}$. UUnhealthy days=number of days of poor emotional health and number of days of poor physical health combined. (A) overall health status ${ }^{*}(B)$ number of healthy days in the last month $\dagger$ (C) number of unhealthy daysł in the last month†. AR, allergic rhinitis; VAS, visual analogue scale.

the AR symptoms were that day. The results were counterintuitive to what would have been expected. AR symptoms were reported as being more bothersome in those children who had taken their medication that day compared with those who had not. While these data could be interpreted to mean that the medication taken had not worked, it is more likely (based on the order of the questions) that the children had been given medication because their symptoms had been bothersome that day. This is consistent with an approach of treating to alleviate the impact of AR, rather than based on disease severity. Community pharmacy research, conducted among Australian adults with AR has demonstrated that the majority $(70 \%)$ selfselect over-the-counter medications, but only $15 \%$ select an appropriate medication for their condition based on symptom severity. ${ }^{31}{ }^{32}$ Symptom severity was found not to be a driving factor in medication choice, with patients reporting that they only sought advice from the pharmacist when they perceived their symptoms to be sufficiently bothersome to impact on their day-to-day lives. ${ }^{33}$

This study has a number of limitations. The survey questionnaire was custom-designed for this research activity and was not validated in its entirety prior to use. However, it drew on a combination of validated tools and questions previously used in similar surveys in paediatric AR. The term 'burden' was used to discuss the effect of AR on health and 'impact' to discuss its effect on activities of day-to-day living, such as schooling and sleep. The measures of burden are determined based largely on the CDC Healthy Days questionnaire ${ }^{17}$ and the measures of impact on questions in the Pediatric Allergies in America Study. ${ }^{18}$ Validity of the use of the single question to measure health status is supported in the literature ${ }^{16}$ and has previously been adapted and used in the AR setting to enable an adult to answer on behalf of a child in their care ${ }^{18}$ Where possible, the survey questionnaire used VAS scales; thereby conforming to established, quantitative methods in other areas of AR research as a valid measure. ${ }^{34-36}$ The representativeness of the sample to that of the Australian population has been difficult to verify given the limited amount of participant demographic data collected. Based on the available data, the sample was slightly older, had a higher level of education and a higher household income than average Australians. This may have occurred due to the online nature of the survey methodology and may have introduced some bias, given that we found a higher household income was associated with an increased propensity to treat AR. The study was set up to collect parental perceptions rather than the 


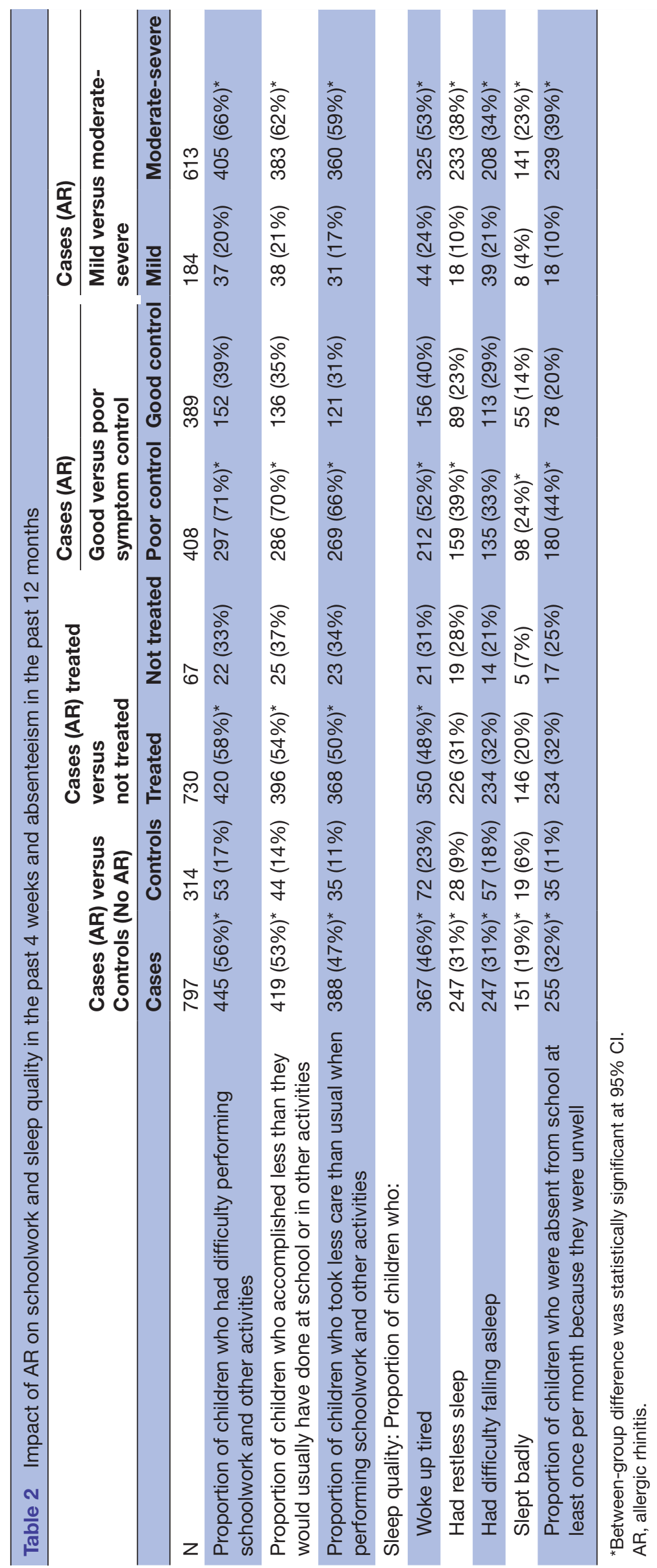


views of children, this may have posed some limitations on the validity reliability of the data, due to proxy reporting bias, particularly in adolescents who were not given the opportunity to answer for themselves.

The PIAF study demonstrated the impact of parental asthma, eczema and AR on the odds of their offspring developing these conditions. ${ }^{13}$ Similarly, in our study, children with AR were significantly more likely to report a range of medical conditions (eg, asthma, cough, eczema, sinusitis and food allergy) in the family (parents/siblings and proband children) relative to children without AR. However, the survey questionnaire listed conditions for the respondents to select from, potentially introducing reporting bias, and there were no clinical examinations or objective tests to verify a diagnosis of AR, both of which limit the interpretation of the data.

In moving forward with the findings of this research, it is important to consider the implications in context with available AR management guidelines. ARIA guidelines developed over the past 20 years have incorporated evidence-based, integrated care approaches to AR management. Increased understanding of the importance of impact and adequacy of control to sufferers has lead to a paradigm shift. ${ }^{37}$ In recent years, the MACVIAARIA Sentinel NetworK has developed and validated VAS scales to evaluate the extent of AR symptom control. ${ }^{3}{ }^{25}$ Well-controlled AR has previously been defined as a VAS of score of 2 or less. ${ }^{38}$ The new ARIA guidelines for adults and adolescents recommend a step-up/step-down algorithm based on patient-report of symptom control assessed via a VAS, with a step-down if the score is $<2$, continuing as is for scores of $\geq 2$ to $<5$, and stepping up if the score is $\geq 5$. ${ }^{2}$ The rationale being that better reflecting patients' needs and preferences will improve overall patient satisfaction and adherence, thereby optimising management. Given the availability of over-the-counter allergy medicines, and high levels of self-diagnosis and self-management of AR, the principles behind these guidelines and the use of VAS scales for self-assessment have been incorporated into care pathways, algorithms and shared decision support systems for use in the community pharmacy setting. ${ }^{3739} \mathrm{~A}$ recent review of AR adds to this, supporting the view that shared decision-making can help to better equip patients to make appropriate decisions for optimal disease control. $^{40}$

Prior research has demonstrated that children with AR as young as 8 years of age are able to use self-assessment questionnaires, including VAS scales to report measures of disease severity and impact. ${ }^{41}$ The availability of appbased self-assessment tools, such as the MASK-Air Allergy Diary, opens up the concept that some children may be able to take a more active role in documenting the impact of the AR, providing opportunities to enhance shared decision making.

\section{CONCLUSION}

The parent-perceived burden of AR in Australian children aged 6 to 15 years is high and impacts many areas of day-to-day living, including emotional well-being, physical health, school and sleep. Inadequate symptom control is a key driver of the extent of that impact. Parents have many misconceptions about AR and its management. Opportunities to optimise the management of AR in children include parental education, regular review and adoption of self-assessment tools to gauge and monitor adequacy of symptom control.

\section{Author affiliations}

'Department Lead, Quality Use of Medicines Group, Woolcock Institute of Medical Research, University of Sydney, Sydney Local Health District, Sydney, New South Wales, Australia

${ }^{2}$ Professor of Clinical Medicine, Griffith University, Southport, Queensland, Australia ${ }^{3}$ Professor of Clinical Epidemiology, School of Public Health and Preventive Medicine, Monash University and Honorary Medical Officer in Respiratory Medicine, Alfred Hospital, Melbourne, Victoria, Australia

${ }^{4}$ General Practitioner \& Head of Primary Care Research, University of Notre Dame, Australia (Sydney School of Medicine), Sydney \& Director Asthma Foundation,

Sydney, New South Wales, Australia

${ }^{5} \mathrm{Head}$ of Central Medical Operations, Real World Clinical Evidence, Sanofi Australia/ New Zealand, Sydney, Australia

${ }^{6}$ Formerly Head of Medical Affairs, Sanofi Consumer Healthcare, Sydney, New South Wales, Australia

${ }^{7}$ Managing Director, Observational and Pragmatic Research Institute, Singapore ${ }^{8}$ Centre of Academic Primary Care, Division of Applied Health Sciences, University of Aberdeen, Aberdeen, UK

Twitter Charlotte Mary Hespe @runningdoc14

Acknowledgements The authors would like to thank Dr Pascal Bourgeat for his input into the study design and statistical analysis plan, who passed away before the completion of the study fieldwork. Professional writing assistance in the preparation of this manuscript was provided by Hazel Palmer of Scriptix, and statistical analyses were performed by Erika Graetz of Ipsos. Both were funded by Sanofi Aventis Healthcare, Australia.

Contributors The following provides a summary of the contributions of each of the authors: SB-A, PS, MA, CMH, DBP, MJ and RS conceived the concept of this work and designed the study. SBA conceived the initial survey questions upon which this research is based. PS, MA, CMH, DBP, MJ and RS further refined the survey questions prior to ethics review and approval. SB-A, PS, DBP, MA and CMH were involved in the conduct of the study; data collection was undertaken by Ipsos. SB-A, PS, MA, CMH, DBP, MJ and RS directed the analysis of the data. SB-A, PS, MA, CMH, $\mathrm{DBP}, \mathrm{MJ}$ and RS contributed to the interpretation of the results. SB-A, PS, MA, CMH, $\mathrm{DBP}, \mathrm{MJ}$ and RS contributed to an outline from which the manuscript was drafted. SB-A, PS, MA, CMH, DBP, MJ and RS revised the manuscript critically for important intellectual content and gave final approval to the version to be published. SB-A accepts full responsibility for this work, had access to the data and controlled the decision to publish.

Funding This study was sponsored by Sanofi Aventis Healthcare, Australia, (Study Number DIREGL09198), which had input into the concept, study design, data analyses, data interpretation and preparation of this report. The study sponsor markets fexofenadine (Telfast). SBA, PS, DP, MJA and CH received honoraria from Sanofi Aventis Healthcare, Australia, for their involvement in an initial working group to determine the parameters of this research project. The authors were responsible for all content, the interpretation of the data and the decision to publish the results; they received no honoraria related to the development of this manuscript. The sponsor funded statistical and editorial assistance and reviewed the final draft before submission. Statistical analyses were performed externally (Erika Graetz of Ipsos). Editorial assistance in the preparation of this manuscript was provided by Hazel Palmer of Scriptix.

Competing interests All authors have completed the International Committee of Medical Journal Editors (ICMJE) uniform disclosure form at www.icmje.org/ coi_disclosure.pdf and declare: SB-A reports personal fees, non-financial support and other support from Sanofi Aventis Healthcare, Australia, during the conduct of the study, grants and personal fees from Teva, personal fees from AstraZeneca, personal fees from Boehringer Ingelheim, personal fees from GlaxoSmithKline, personal fees from Sanofi, and grants and personal fees from Mylan outside the 
submitted work. PS reports personal fees and non-financial support from Sanofi Aventis Healthcare, Australia, during the conduct of the study, grants and personal fees from Meda, personal fees from Glaxo Smith Kline, and personal fees and other from Astra Zeneca outside the submitted work. DBP reports personal fees and nonfinancial support from Sanofi Aventis Healthcare, Australia, during the conduct of the study, personal fees from Amgen, grants and personal fees from Astra Zeneca, grants and personal fees from Boehringer Ingelheim, grants and personal fees from Chiesi, grants and personal fees from Circassia, personal fees from Cipla, personal fees from Glaxo Smith Kline, personal fees from Kyorin, grants and personal fees from Mylan, grants and personal fees from Mundipharma, grants and personal fees from Novartis, grants and personal fees from Pfizer, grants and personal fees from Regeneron Pharmaceuticals, grants from Respiratory Effectiveness Group, grants and personal fees from Sanofi Genzyme, grants and personal fees from Teva, grants and personal fees from Theravance, personal fees from Thermo Fisher, grants from UK National Health Service, non-financial support from Efficacy and Evaluation Mechanism Programme, and non-financial support from Health Technology Assessment, outside the submitted work; and stock/stock options from AKL Research and Development which produces phytopharmaceuticals; and owns $74 \%$ of the social enterprise Optimum Patient Care (Australia and UK) and $74 \%$ of Observational and Pragmatic Research Institute (Singapore). MA reports personal fees, non-financial and other support from Sanofi Aventis Healthcare, Australia, during the conduct of the study, grants from Pfizer, grants from Boehringer-Ingelheim, and personal fees from GlaxoSmithKline, outside the submitted work. CMH reports personal fees and non-financial support from Sanofi Aventis Healthcare, Australia, during the conduct of the study, grants from Amgen, other from Glaxo Smith Kline, and other from Pfizer outside the submitted work. MJ is an employee of Sanofi, Australia, reports personal fees from Sanofi, Australia, both during the conduct of the study and outside the submitted work. RS was an employee of Sanofi Aventis Healthcare, Australia, at the time this work was carried out and reports personal fees from Sanofi Aventis Healthcare, Australia, both during the conduct of the study and outside the submitted work.

Patient consent for publication Not required.

Ethics approval Bellberry Human Research Ethics Committee (Eastwood, South Australia, Australia) approved the study.

Provenance and peer review Not commissioned; externally peer-reviewed.

Data availability statement Extra data is available upon reasonable request and with permission of Sanofi Australia Pty Ltd by emailing sinthia.bosnic-anticevich@ sydney.edu.au. There are no plans to disseminate the results to the study participants.

This content has been supplied by the author(s). It has not been vetted by BMJ Publishing Group Limited (BMJ) and may not have been peer-reviewed. Any opinions or recommendations discussed are solely those of the author(s) and are not endorsed by BMJ. BMJ disclaims all liability and responsibility arising from any reliance placed on the content. Where the content includes any translated material, BMJ does not warrant the accuracy and reliability of the translations (including but not limited to local regulations, clinical guidelines, terminology, drug names and drug dosages), and is not responsible for any error and/or omissions arising from translation and adaptation or otherwise.

Open access This is an open access article distributed in accordance with the Creative Commons Attribution Non Commercial (CC BY-NC 4.0) license, which permits others to distribute, remix, adapt, build upon this work non-commercially, and license their derivative works on different terms, provided the original work is properly cited, appropriate credit is given, any changes made indicated, and the use is non-commercial. See: http://creativecommons.org/licenses/by-nc/4.0/.

\section{ORCID iDs}

Sinthia Bosnic-Anticevich http://orcid.org/0000-0001-5077-8329

David B Price http://orcid.org/0000-0002-9728-9992

\section{REFERENCES}

1 Bousquet J, Van Cauwenberge P, Khaltaev N, et al. Allergic rhinitis and its impact on asthma. J Allergy Clin Immunol 2001;108:S147-334.

2 Bousquet J, Schünemann HJ, Togias A, et al. Next-Generation allergic rhinitis and its impact on asthma (ARIA) guidelines for allergic rhinitis based on grading of recommendations assessment, development and evaluation (grade) and real-world evidence. $J$ Allergy Clin Immunol 2020;145:70-80.
3 Bousquet J, Schunemann HJ, Fonseca J, et al. MACVIA-ARIA sentinel network for allergic rhinitis (MASK-rhinitis): the new generation guideline implementation. Allergy 2015;70:1372-92.

4 de Wit M, Hajos T. Health-related quality of life. In: Gellman MD, Turner JR, eds. Encyclopedia of behavioral medicine. New York, USA: Springer, 2013: 929-31.

5 Blaiss MS, Hammerby E, Robinson S, et al. The burden of allergic rhinitis and allergic rhinoconjunctivitis on adolescents: a literature review. Ann Allergy Asthma Immunol 2018;121:43-52.

6 Meltzer EO, Gross GN, Katial R, et al. Allergic rhinitis substantially impacts patient quality of life: findings from the nasal allergy survey assessing limitations. J Fam Pract 2012;61:S5-10.

7 Karimi M, Brazier J, Health BJ. Health, health-related quality of life, and quality of life: what is the difference? Pharmacoeconomics 2016;34:645-9.

8 Meltzer EO. Quality of life in adults and children with allergic rhinitis. $J$ Allergy Clin Immunol 2001;108:S45-53.

9 Robertson CF, Roberts MF, Kappers JH. Asthma prevalence in Melbourne school children: have we reached the peak? Med J Aust 2004;180:273-6.

$10 \mathrm{Kim} \mathrm{J}$-L, Brisman J, Aberg MA, et al. Trends in the prevalence of asthma, rhinitis, and eczema in 15 year old adolescents over an 8 year period. Respir Med 2014;108:701-8.

11 Pols DHJ, Wartna JB, Moed H, et al. Atopic dermatitis, asthma and allergic rhinitis in general practice and the open population: a systematic review. Scand J Prim Health Care 2016;34:143-50.

12 Hill DA, Grundmeier RW, Ram G, et al. The epidemiologic characteristics of healthcare provider-diagnosed eczema, asthma, allergic rhinitis, and food allergy in children: a retrospective cohort study. BMC Pediatr 2016;16:133.

13 Owens L, Laing IA, Zhang G, et al. Prevalence of allergic sensitization, hay fever, eczema, and asthma in a longitudinal birth cohort. J Asthma Allergy 2018;11:173-80.

14 Katelaris $\mathrm{CH}$, Sacks R, Theron PN. Allergic rhinoconjunctivitis in the Australian population: burden of disease and attitudes to intranasal corticosteroid treatment. Am J Rhinol Allergy 2013;27:506-9.

15 International Study of Asthma and Allergies in Childhood (ISAAC). Phase three core questionnaire, 2020. Available: http://isaac. auckland.ac.nz/phases/phasethree/corequestionnaire.pdf

16 Bowling A. Just one question: if one question works, why ask several? J Epidemiol Community Health 2005;59:342-5.

17 Centers for Disease Control and Prevention. Measuring healthy days. Atlanta, Georgia: CDC, November 2000, 2020. Available: https:// www.cdc.gov/HRQoL/pdfs/mhd.pdf

18 Meltzer EO, Blaiss MS, Derebery MJ, et al. Burden of allergic rhinitis: results from the pediatric allergies in America survey. J Allergy Clin Immunol 2009;124:S43-70.

19 Smith H, Llewellyn C, et al. Understanding patients' experiences of hayfever and its treatment: a survey of illness and medication cognitions. J Allergy Ther 2012;1:1-7.

20 Alreshidi FM, Alrashidi AS, Alshammari FNM, et al. Knowledge, attitude and practice about allergic rhinitis in Saudi Arabia, 2017. Egyptian Journal of Hospital Medicine 2017;69:2199-203.

21 Rajasekaran V, Knowledge GP. Attitude and practice about allergic rhinitis in a rural population, Kancheepuram district, Tamil Nadu. Int $J$ Otolaryngol Head Neck Surg 2018;4:159-62.

22 Zhao J, Shen K, Xiang L, et al. The knowledge, attitudes and practices of parents of children with asthma in 29 cities of China: a multi-center study. BMC Pediatr 2013;13:20.

23 Jáuregui I, Dávila I, Sastre J, et al. Validation of ARIA (allergic rhinitis and its impact on asthma) classification in a pediatric population: the PEDRIAL study. Pediatr Allergy Immunol 2011;22:388-92.

24 Klimek L, Bergmann K-C, Biedermann T, et al. Visual analogue scales (VAS): measuring instruments for the documentation of symptoms and therapy monitoring in cases of allergic rhinitis in everyday health care: position paper of the German society of allergology (AeDA) and the German society of allergy and clinical immunology (DGAKI), ENT section, in collaboration with the working group on clinical immunology, allergology and environmental medicine of the German society of otorhinolaryngology, head and neck surgery (DGHNOKHC). Allergo J Int 2017;26:16-24.

25 Caimmi D, Baiz N, Tanno LK, et al. Validation of the MASK-rhinitis visual analogue scale on smartphone screens to assess allergic rhinitis control. Clin Exp Allergy 2017;47:1526-33.

26 Borrego LM, Fonseca JA, Pereira AM, et al. Development process and cognitive testing of CARATkids - Control of Allergic Rhinitis and Asthma Test for children. BMC Pediatr 2014;14:34.

27 Meltzer EO, Farrar JR, Sennett C. Findings from an online survey assessing the burden and management of seasonal allergic Rhinoconjunctivitis in US patients. J Allergy Clin Immunol Pract 2017;5:779-89. 
28 Bédard A, Basagaña X, Anto JM, et al. Mobile technology offers novel insights into the control and treatment of allergic rhinitis: the mask study. J Allergy Clin Immunol 2019;144:135-43.

29 May JR, Dolen WK. Management of allergic rhinitis: a review for the community pharmacist. Clin Ther 2017;39:2410-9.

30 Australasian Society of Clinical Immunology and Allergy (ASCIA). Allergic rhinitis clinical update: 2020, 2020. Available: https://www. allergy.org.au/images/stories/pospapers/ar/ASCIA_HP_Clinical_ Update_Allergic_Rhinitis_2020.pdf

31 Tan R, Cvetkovski B, Kritikos V, et al. Identifying the hidden burden of allergic rhinitis (AR) in community pharmacy: a global phenomenon. Asthma Res Pract 2017;3:8 https://doi.org/

32 Carney AS, Price DB, Smith PK, et al. Seasonal patterns of oral antihistamine and intranasal corticosteroid purchases from Australian community pharmacies: a retrospective observational study. Pragmat Obs Res 2017;8:157-65.

33 Tan R, Cvetkovski B, Kritikos V, et al. Management of allergic rhinitis in the community pharmacy: identifying the reasons behind medication self-selection. Pharm Pract 2018;16:1332-32.

34 Bousquet PJ, Combescure C, Neukirch F, et al. Visual analog scales can assess the severity of rhinitis graded according to ARIA guidelines. Allergy 2007;62:367-72.
35 Bousquet J, Bachert C, Price D, et al. Assessing allergic rhinitis symptom control using a simple visual analogue scale: the digital solution (MACVIA-ARIA). Allergy 2014;69:1-646.

36 Bousquet J, Arnavielhe S, Bedbrook A, et al. The allergic rhinitis and its impact on asthma (ARIA) score of allergic rhinitis using mobile technology correlates with quality of life: the mask study. Allergy 2018;73:505-10.

37 Lourenço O, Bosnic-Anticevich S, Costa E, et al. Managing allergic rhinitis in the pharmacy: an ARIA guide for implementation in practice. Pharmacy 2020;8:85.

38 Bousquet J, Schünemann HJ, Hellings PW, et al. MACVIA clinical decision algorithm in adolescents and adults with allergic rhinitis. $J$ Allergy Clin Immunol 2016;138:367-74.

39 Bosnic-Anticevich S, Costa E, Menditto E, et al. ARIA pharmacy 2018 "Allergic rhinitis care pathways for community pharmacy". Allergy 2019;74:1219-36.

40 Steven GC. Shared decision making in allergic rhinitis: an approach to the patient. Ann Allergy Asthma Immunol 2020;125:268-72.

41 Pizzulli A, Perna S, Florack J, et al. The impact of telemonitoring on adherence to nasal corticosteroid treatment in children with seasonal allergic rhinoconjunctivitis. Clin Exp Allergy 2014;44:1246-54. 